\title{
MENOSPRECIO DE CORTE Y ALABANZA DE ALDEA EN LA NOVELA DE FINALES DEL SIGLO XVIII
}

\author{
MARC MARTI \\ CNA, Universidad de Niza
}

\begin{abstract}
Según J. Álvarez Barrientos, la narrativa dieciochesca se caracterizó por una progresiva y cada vez más afirmada secularización. Al estudiar los problemas que planteó la nueva novela a los preceptistas neoclásicos, subraya que «era un género distinto, que no cabía en los márgenes del clasicismo». Concluye que «en todos los casos se puede percibir la tensión que conlleva el intento de explicar desde criterios neoclásicos un género nuevo que no se ajusta a ninguno de los principios constitutivos del ordenamiento estético clasicista, si salvamos el componente didáctico propio de casi toda la literatura de la época» ${ }^{1}$. A la luz de esas conclusiones, proponemos estudiar la evolución del topos del «menosprecio de corte y alabanza de aldea» en cinco novelas de finales del siglo XVIII, considerándolo a la vez como instrumento de representación del espacio y como lugar común moral ${ }^{2}$. No atribuimos ningún valor peyorativo al término «lugar común». Aunque poco a poco en la creación literaria los lugares comunes o topoi koinoi fueron considerados negativamente, en nombre de la originalidad, tal concepción es, en cierta medida, anacrónica para la literatura dieciochesca ${ }^{3}$. Por otra parte, en el marco de la historia literaria, el análisis de los topoi y de su evolución puede proporcionar al investigador datos sobre la evolución de los géneros y la especificidad literaria de una época.
\end{abstract}

\footnotetext{
1 Joaquín ÁlVAREZ BARRIENTOS, «La narrativa del siglo XVIII» en Guillermo CARNERO (coordinador) Historia de la literatura española. Siglo XVIII, Madrid, Espasa Calpe, 1995 pp. 911 y 916.

2 Para el término topos seguiremos la definición que da el Diccionario de retórica, crítica y terminología literaria, de Angelo MARCHESE, traducida por Joaquín FORRADELLAS, Barcelona, Ariel, 1994, p. 407: «El topos es un motivo o la configuración estable de varios motivos que son usados con cierta frecuencia por los escritores y, sobre todo, por los oradores que necesitan «materiales» genéricos, de hallazgo fácil. El topos es un «lugar común» [...] La tópica es el código de estas formas estereotipadas, temas consagrados, enunciaciones convencionales».

3 Ruth AmOSSY, Anne HERSCHBERG PIERrot, Stéréotypes et clichés, langue, discours, société, Paris, Nathan, 1997, p. 15.
} 
En efecto, si la nueva narrativa no podía caber en los moldes neoclásicos, recuperó sin embargo algunos topoi de los géneros tradicionales, teatro o poesía. Pero no se trató de ajustar las narraciones a marcos clásicos sino que los estereotipos tradicionales fueron revitalizados por los autores que muchas veces los transformaron en estructuras narrativas marcadas por su época. Proponemos aquí un análisis de este proceso de asimilación y de transformación a través de unos cuantos ejemplos de novelas de finales del siglo XVIII.

\section{UN TOPOS CLÁSICO Y UN CONTEXTO FAVORABLE}

El tratado de Antonio de Guevara Menosprecio de Corte y alabanza de aldea definió los elementos del topos en el siglo XVI ${ }^{4}$. Éste tenía sin embargo un origen anterior, que se puede situar en la poesía latina, con el Beatus ille de Horacio o las Geórgicas de Virgilio.

El topos apareció también en la prosa moral durante la primera parte del siglo XVIII, como en la obra de Antonio Muñoz de 1737, Morir viviendo en la aldea o vivir muriendo en la Corte. En la segunda parte de la centuria, los poetas volvieron a introducir el tema en composiciones anacreónticas y pastoriles, pero combinándolo con un elogio de una naturaleza sensual, a menudo evocada a través del locus amonus ${ }^{5}$. Aunque no se puede considerar como referencia absoluta, el romance del duque de Béjar, La vida de la aldea, escrito para la Academia del Buen Gusto y fechado de 1750, revela el nuevo interés por este tema clásico. En esta composición, el poeta se interroga sobre el modelo que seguir, revelando claramente el doble origen del estereotipo:

$$
\begin{aligned}
& \text { «Usurparé a tanto asunto } \\
& \text { De la pastoril Euterpe } \\
& \text { La zampoña, o de Guevara } \\
& \text { El clarín más elocuente» }{ }^{6} \text {. }
\end{aligned}
$$

Dos decenios más tarde, el topos será imprescindible: anacreónticas, églogas, odas y otras composiciones cantaban las alabanzas de la vida rural. El tema del concurso propuesto por la Real Academia en julio de 1779,

4 Sobre la estructuración del topos a través de figuras de oposición como oxímoron, antítesis, paralelismo o paradoja, véase la introducción crítica de Asunción RALLo a la obra de Antonio de Guevara, Menosprecio de Corte y Alabanza de Aldea, Madrid, Cátedra, 1984, p. 61.

5 Véase David T. GIES, «La poesía del siglo XVIII (I). El Rococó poético» en Guillermo CARNERO, op. cit., pp. 221-227.

6 DUQue DE BÉJAR, La vida de la aldea, Madrid, Atlas, 1953, BAE, tomo LXVII, p. 503. 
una égloga que cantase las excelencias de la vida en el campo, reflejaba aquel ambiente ${ }^{7}$. El hecho de que acudiesen quince poetas, algunos ya famosos, demostraba la actualidad de la temática. Fuera de la polémica literaria que engendraron, las dos églogas premiadas, la de Tomás de Iriarte y la de Juan Meléndez Valdés, revelaban el doble valor del tópico. El canario prefirió el aspecto moral y racional mientras que el extremeño se inclinó por el bucolismo. Dos aspectos que, a su vez, la novela iba a utilizar.

\section{LA NOVELA Y EL TOPOS COMO NÚCLEO NARRATIVO}

La creación novelística recuperó el topos en algunas obras para integrarlo de manera dinámica en el desarrollo narrativo.

En El Mirtilo o los pastores trashumantes, la tardía novela pastoril de Montengón, el «menosprecio de corte» sirve de punto de partida a la narración. El protagonista principal abandona la ciudad donde no se reconoció su talento. Durante la trashumancia que estructura el relato, se repite de vez en cuando el tópico «menosprecio de corte y alabanza de aldea», sea en las poesías intercaladas, sea en la prosa ${ }^{8}$. El lugar edénico, descubierto por Mirtilo al final de la obra, marca el contrapunto del «menosprecio de corte» que iniciaba el relato. En esta novela, como era de esperar, el autor escogió el estereotipo bucólico y pastoril. Pero a la par cuestionó, en nombre de preocupaciones económicas ilustradas, el mundo ficticio de los pastores, planeando, a través de sus personajes, la desaparición del ganado trashumante. La profecía del mago Ortón anuncia un futuro poco prometedor para el ganado:

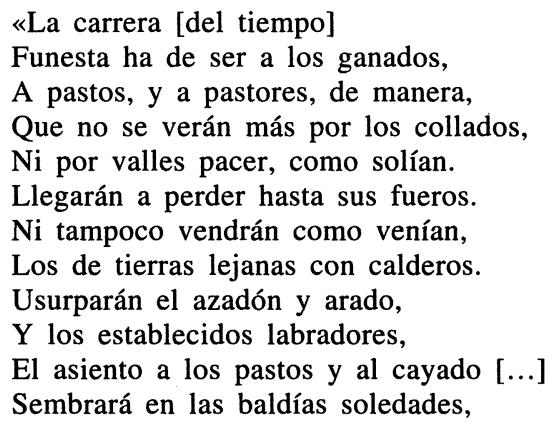

7 Francisco AgUilar PIÑAL, «Poesía», en Francisco AgUILAR PIÑal (coordinador), Historia literaria del siglo XVIII, Madrid, Trotta-CSIC, 1996, p. 78.

8 Sobre la estructura espacial de esta novela, véase nuestro trabajo, Marc MARTI, «L'espace pastoral à l'épreuve de l'Histoire, étude narratologique du roman de Pedro Montengón El Mirtilo o los pastores trashumantes», Cahiers de narratologie, n. ${ }^{\circ} 7$, Mélanges espace et temps, Nice, 1996, pp. 49-62. 
La gran mano del tiempo, como trigo,

Torreadas aldeas y ciudades $[\ldots]{ }^{9}$.

A pesar de haber disfrutado de una vida «de paz y dulzura», el propio Mirtilo pone en tela de juicio la trashumancia al llegar al final del viaje:

«Como era la primera vez que Mirtilo llegaba allí, extrañaba mucho el ver aquel rico y fértil suelo, y Reino, poblado sólo de advenedizos pastores, sabiendo él que era una de las provincias más pobladas y florecientes en tiempo de los Romanos [...]

De esto trataba Mirtilo con Silvanio, maravillándose que de tantos años atrás, no se hubiese jamás pensado en remediar la falta de población de aquel suelo capaz de mantener millares de habitadores, que con su industria, comercio y artes, acrecentarían su riqueza natural, que por sí sola sería muchas veces mayor a la que España percibía de todos sus ganados; pues por grande que fuese la utilidad de las lanas, y de las crías, no equivaldría de mucho a sólo los productos que pudieran dar tantos terrenos baldíos, y destinados a los pastos, si en vez de éstos, estuviesen poblados y cultivados [...]

A esto añadía Mirtilo que le parecía padecer engaño aquellos que atribuían la falta de población de aquel Reino a los ganados, y a los fueros de los ganaderos que los conducían a invernar; pues juzgaba que esto era, al contrario, efecto de la despoblación misma, y no causa de ella [...]»

Decía también que España no perdería sus lanas, aunque cesasen las trashumaciones de los pastores, como no las perdía Inglaterra, donde no había tales emigraciones invernales $[\ldots]{ }^{10}$.

Hay aquí una clara relación entre la visión del protagonista principal y las críticas contra la Mesta que aparecían en textos económicos anteriores, como el Memorial ajustado o el Informe sobre la ley agraria que redactó Pablo de Olavide ${ }^{11}$. Es interesante notar que Montengón utilizó, a través del discurso de Mirtilo, el ejemplo de Inglaterra, como Olavide en $1768^{12}$.

9 Pedro Montengón, El Mirtilo o los pastores trashumantes, Madrid, Sancha, 1795, pp. 52-53.

10 Pedro MonTEngón, El Mirtilo..., pp. 264-266.

11 Memorial ajustado sobre los males que padece la Agricultura, sus motivos, y medios para su restablecimiento y fomento; y del que se le ha unido, suscitado a instancia del Illmo Señor C. de Campomanes, sobre establecimiento de una ley agraria, y particulares que deberá comprender, para facilitar el aumento de la Agricultura y de la población, y proporcionar la posible igualdad a los vasallos en el aprovechamiento de las tierras, para arraygarles y fomentar su industria; en cuyo informe han participado los intendentes de Soria, Burgos Ávila, Ciudad Rodrigo, Granada, Córdoba, Jaén, Ciudad Real, Sevilla y el decano de la Real Audiencia de esta ciudad, 1767.

El texto de Olavide sobre la Ley Agraria fue escrito en las mismas fechas y fue utilizado por la Sociedad Económica Matritense en su clase de agricultura. Existe una edición realizada por Ramón CARANDE y Joaquín RUIZ, «Informe de don Pablo de Olavide sobre la Ley Agraria», Boletín de la Real Academia de Historia, octubre-diciembre 1956, pp. 357-463.

12 Véase Pablo de OLAVIDE, «Informe de Pablo de Olavide sobre la Ley Agraria», pp. 380-381. 
Esta novela refleja bastante bien la evolución que conoce el género, como lo ha analizado Joaquín Álvarez Barrientos ${ }^{13}$. En efecto, la trama pastoril según la entendía la tradición clásica, era imitación de lo universal, pero Montengón, consciente o inconscientemente, no podía quedar satisfecho con tal limitación. La introducción de los temas de reforma agraria en el Mirtilo serían pues un intento de imitar la realidad presente, pero utilizando un modelo narrativo que era seguramente uno de los más inadecuados para tal proyecto ${ }^{14}$.

Más allá del caso del Mirtilo, la «alabanza de aldea» fue una constante en las novelas de Montengón. En Eudoxia hija de Belisario, los protagonistas principales deciden, al final de la novela, vivir en el campo y renunciar a la vida cortesana, a pesar de la rehabilitación de Belisario por el emperador. El narrador concluye:

«Así, mientras otros, inducidos de los ciegos anhelos de la vanidad y de la ambición, desamparan sus antiguos solares por ir a gozar del trato y divertimientos en las ciudades, Eudoxia y Maximio, instruidos de la desgracia, buscaron en el campo su más deliciosa y apreciable morada, lejos de los continuos disgustos y mareos de la sociedad, vacía de sólido provecho y llena de disgustos y congojas» ${ }^{15}$.

En Eudoxia como en El Mirtilo, el «menosprecio de corte y alabanza de aldea» constituye el verdadero núcleo narrativo de la obra. El topos clásico, tomado de la poesía y de los tratados morales, se transforma en estructura narrativa y motiva el trayecto espacial de los personajes en las dos novelas. En ambas obras, la vida en el campo supone ante todo la puesta en práctica de un ideal moral ejemplar. Sin embargo, en otras ficciones, este modelo de vida es completado por un proyecto económico agrícola ilustrado.

\section{LA NOVELA Y EL TOPOS COMO TEMÁTICA ECONÓMICA}

Durante el mismo periodo, encontramos episodios inspirados del tópico $\mathrm{y}$ en los cuales aparece un acomodado propietario, que ha escogido residir voluntariamente en el campo. Pero ya no se trata de vivir como un

\footnotetext{
13 Joaquín Álvarez BARRIENTOS, La novela del siglo XVIII, Madrid, Júcar, 1991, p. 389.

14 Véase el acertado comentario de Joaquín Álvarez BARRIENTos a propósito de Montengón, en La novela del siglo XVIII, p. 242: «Su rigidez preceptiva, nacida de estar sujeto a los criterios preceptivos clasicistas, le lleva a no entender adecuadamente las posibilidades de la novela $\mathbf{y}$, así, a refugiar sus capacidades narrativas en estructuras antiguas como las del poema épico y la novela pastoril».

15 Pedro MonTENGón, Eudoxia, hija de Belisario, [1793], edición de Guillermo Carnero, Instituto de Cultura Juan Gil-Albert, Alicante, 1990, p. 285.
} 
ermita o un virtuoso cristiano, como se podía imaginar en los siglos precedentes, sino como un verdadero ilustrado. Este tipo de personaje aparece en algunas novelas, a veces de manera bastante inesperada. Es el caso en la novela de aventuras El Valdemaro de Vicente Martínez Colomer, en la que «apoyándose en la estructura del relato bizantino, el autor se embarca en una historia de corte fantástico en la que a personajes ilustres y nobles, reyes y herederos destronados, se unen magos y elementos fantásticos» ${ }^{16}$. Durante su largo viaje, el héroe topa con un anciano llamado Gésner, (referencia al famoso autor suizo), que ha difundido sus conocimientos agrícolas entre los miserables habitantes de una comarca, fomentando su desarrollo económico:

\begin{abstract}
«Advirtiendo que sólo pastaban tan amena y dilatada vega dos o tres rebaños de ovejas y que la tierra virgen sólo producía frutos silvestres y algunas pocas legumbres, les fui instruyendo poco a poco en el modo de aumentar el ganado, de cultivar la tierra, de hacerla producir abundantes cosechas, de podar los árboles y de injertarlos para que diesen sazonados y dulces frutos» ${ }^{17}$.
\end{abstract}

El comportamiento de Gésner es el de un ilustrado que adopta una actitud activa frente a la realidad del campo ${ }^{18}$. Éste no es sólo un refugio para una vida ejemplar y la búsqueda personal de la felicidad espiritual sino también un espacio en el que se quiere conseguir la felicidad material para los demás y para sí mismo:

«Así vivo feliz entre estas sencillas gentes que me honran llamándome su soberano. La paz se ha establecido en esta dichosa morada y el contento jamás se aleja de ella» ${ }^{19}$.

Entre las novelas de Montengón, Eusebio es el mejor ejemplo de la utilización del topos para presentar un proyecto agrícola en el campo. En la cuarta parte, casado ya con Leocadia, decide Eusebio «pasar todo el verano en la granja para atender mejor a su cultivo y cosecha, queriendo ser [...] el administrador de sus haciendas» ${ }^{20}$. Allí va a perfeccionar los adelantos que introdujo su preceptor Hardyl:

16 Joaquín Álvarez Barrientos, «Novela» en Francisco Aguilar PiÑAl, op. cit., p. 262.

17 Vicente Martínez COLOMER, El Valdemaro [1792], edición de Guillermo Carnero, Alicante, Instituto de Estudios Juan Gil Alberto, 1985, pp. 86-87.

18 Estudiamos sólo este episodio, pero como lo señala Guillermo Carnero en el estudio preliminar (pp. 37-38) la alabanza de aldea y menosprecio de corte se repite en los libros I, II y IV.

19 Vicente MARTínez COLOMER, El Valdemaro, p. 88.

20 Pedro MONTENGÓN, Eusebio [1786-1788], edición de Fernando García Lara, Madrid, Cátedra, 1998, p. 881. 
«Echó de ver Eusebio que todas aquellas disposiciones que había dado Hardyl antes de dejar la América, algunas quedaban por hacer, otras en embrión, y las más dejadas a cargo del tiempo y de la naturaleza. Requerían por lo mismo todos sus cuidados y los conocimientos que habían adquirido en el viaje sobre el cultivo del campo en los diversos climas y países en que habían estado. Éste fue, pues, el empleo y ocupación a que se dedicó todo el tiempo que estuvo en la granja, reservando para el estudio los días que los malos tiempos le impedían la salida de la casa $[\ldots]{ }^{21}$.

El largo viaje del protagonista, que forma la mayor parte de la novela, es valorado porque le permitió adquirir los conocimientos necesarios para mejorar la agricultura. Los motivos de Eusebio y su actuación en el campo parecen bastante alejados del topos, sin embargo, pocas páginas después, suena el «clarín de Guevara» con algunos acentos contemporáneos:

«No echaba de menos Eusebio en aquella deliciosa soledad el concurso de las ciudades ni de la gente desasosegada; de sus importunas visitas y del trato de los mundanos, que con él no buscan el fomento de la pura satisfacción de la amistad, sino el sacudir de sí mismos el aburrimiento de su ociosidad y de su pesada existencia, y el dar el paso a sus ruines pasiones, ora desahogando los incentivos de la envidia, ora cebando su mordacidad en la ajena desgracia o pobreza; o alimentando los bajos sentimientos de su malicia, o maquinando con ellos el descrédito o la ruina de sus mismos inocentes amigos y conocidos. Lejos de los ejemplos de la codicia y de la ambición, y exento de las desazones e inquietudes que ellas acarrean, disfrutaba su alma la dulce tranquilidad del campo, que le hacía más preciosa y estimable la compañía de Leocadia» ${ }^{22}$.

En efecto, si el «menosprecio de corte» pudiera parecer estereotipado, las referencias a la amistad, al ocio, al aburrimiento, y, sobre todo, la valoración de la compañía de la esposa amada eran elementos que revitalizaban el topos, situándolo claramente en su época.

Las novelas que acabamos de comentar se sitúan entre 1786 y 1792. Su relación con acontecimientos históricos parece clara, lo que ya demuestra la permeabilidad del género respecto a los problemas contemporáneos. Primero, siguiendo la cronología, es evidente que domina la referencia implícita a la experiencia de la colonización de la Sierra Morena. Estos personajes literarios podrían ser la proyección ficticia e idealizada del monarca ilustrado, civilizador del campo. La idea tenía un prolongamiento concreto. Para Campomanes, los adelantos y las reformas agrícolas podían realizarse gracias a la actuación de los grandes propietarios, lo que explica el proyecto y luego la formación de las Sociedades Económicas:

«La Sociedad Económica ha de ser compuesta, para que pueda ser útil, de la nobleza más instruida del país. Ella es la que posee las principales y más

21 Pedro Montengón, Eusebio, p. 884.

22 Pedro MONTENGón, Eusebio, pp. 893-894. 
pingües tierras y tiene el principal interés en fomentar la riqueza del pueblo, cuya industria da valor a sus posesiones.

Cualesquiera fatigas y desvelos que tomen a su beneficio es una retribución debida al valor anual que dan a sus terrenos. Mientras los populares cultivan con gran penalidad los campos, ellos cuidan de que no falte a persona alguna de la tierra industria de que vivir y ocupan gloriosamente, a beneficio de su patria, un tiempo que sus mayores empleaban en la guerra y ahora no aprovechan. Destierran los vicios que trae la ociosidad y todos a porfía trabajan por el engrandecimiento de la Nación. ¡Qué felicidad para un hombre de bien haber nacido con rentas y proporción que le den lugar a la más noble tarea del ciudadano, mientras los demás están dedicados al afán de sus labores! Estas reflexiones tienen lugar con los individuos del Clero y las gentes acaudaladas» ${ }^{23}$.

La novela expresó esta realidad en su estructura, mediante el topos del «menosprecio de corte y alabanza de aldea», adaptando la herencia clásica a los nuevos tiempos. En efecto, es de notar que en El Valdemaro como en Eusebio, la aldea es sustituida por el campo, o más bien la granja, un espacio más adecuado y más verosímil para llevar a cabo los proyectos agrícolas. Por otra parte, también cabe subrayar que en esas dos novelas, el «menosprecio de corte» es sólo un eco lejano, por lo menos en el caso de los proyectos agrícolas concretos. Sin embargo, sirve todavía de contrapunto en el marco del proyecto moral de los novelistas.

Y esas transformaciones de un topos clásico también prefiguran su total readaptación en tramas narrativas en las que se abandona casi completamente el campo como lugar de acción, como es el caso en La Serafina de José Mor de Fuentes.

\section{UN TOPOS ASIMILADO Y SUPERADO}

La Serafina de José Mor de Fuentes es interesante por representar uno de los primeros casos de novela urbana, en una Zaragoza contemporánea del autor. La construcción del espacio en este relato anuncia una evolución del género, a la vez por la abundante toponimia como por las funciones desempeñadas por este marco urbano ${ }^{24}$. Por otra parte, «el menosprecio de corte y alabanza de aldea» aparece totalmente transformado. En efecto, Alfonso, el protagonista principal va a menospreciar la corte en sus pri-

${ }^{23}$ Pedro Rodríguez, CONDE DE CAMPOMANES, Discurso sobre el fomento de la industria popular, Madrid, Clásicos del pensamiento Económico Español, Instituto de Estudios Fiscales, Ministerio de Hacienda, 1975, p. 104.

${ }^{24}$ Véase nuestro trabajo, Marc MARTI, "L'espace dans le roman épistolaire du XVIIIe, La Serafina de José Mor de Fuentes (1797)» in Actes du colloque international, Création de l'espace et narration littéraire, (Séville, mars 1997), Cahiers de narratologie, n. ${ }^{\circ}$, Nice, 1997, pp. 263-276. Las actas en castellano serán publicadas por la Universidad de Sevilla dentro de breve plazo. 
meras cartas, elogiando la ciudad de provincias ${ }^{25}$. Afirma su preferencia por Zaragoza desde la primera carta, en la que pondera las ventajas de la capital aragonesa y de su modesta condición:

« $¡ Q u e ́$ empeño tienes, amado Eugenio, por saber el motivo de mi larga detención en este pueblo! ¿Me quieres en Madrid rindiendo obsequios y haciendo antesalas con la mira de mejorar fortuna? ¿No adviertes cuán incierto es el logro y cuán indudables las incomodidades? ¿Y qué, tanto necesita un hombre para su decorosa subsistencia?» ${ }^{26}$

Pone en tela de juicio unas prácticas cortesanas muy contemporáneas como la de «hacer antesalas» y el mensaje moral, que indica la preferencia de Alfonso por su condición mediocre, es bastante tópico. Sin embargo el «menosprecio de corte» vuelve a encontrarse en la carta 58, con un contenido que sugiere la valoración de cualidades burguesas:

«Si el dinero que se gasta en la Corte para comprar amarguísimos desengaños, se dedicase a mejorar los patrimonios, nuestra labranza sería de las más adelantadas. Me citarán individuos que han logrado fortunas rápidas y monstruosas, y yo responderé sacando para cada uno de ellos, centenares de ejemplos de miseria extrema y desconsuelo perpetuo. Insistirán con el realce que dan los que llaman los honores a las familias; como si el hombre de prendas necesitase el quebradizo oropel de los empleos y de las graduaciones para merecer la estimación propia, que prepondera a la de todo el Universo» ${ }^{27}$.

Es interesante notar que al «oropel de los empleos» se opone un valor burgués de individualidad, «la estimación propia». Por otra parte, si bien aparece la noción de «desengaño», la corte no representa aquí la riqueza, como en el topos tradicional, sino la miseria para los pretendientes.

Otra originalidad en Mor de Fuentes es que, en el marco de la novela, rechaza cualquier idealización de la aldea o del campo. La única excepción es la descripción de la carta 142, pero Alfonso indica que no se refiere a la realidad sino a un sueño ${ }^{28}$. Más generalmente, las descripciones de pastores o de campesinos insisten en su grosería y defectos. Durante una excursión al campo, Alfonso describe así a los pastores:

25 Estudiamos detenidamente el caso de esta novela en cuanto a la representación del campo y de la ciudad en nuestro trabajo de tesis (1994), Marc MARTI, Ville et campagne dans l'Espagne des Lumières (1746-1808), Saint Étienne, 1997. Véanse las pp. 299-302.

26 José MOR DE FUENTES, La Serafina [1797], novela, edición de Manuel Gil, Zaragoza, Caesaraugusta II, 1959, p. 21.

27 José MOR DE FUENTES, La Serafina, p. 96.

28 José MOR DE FUENTES, La Serafina: «Batallando anoche con estos pensamientos, después de un desvelo de los míos, quiero decir, largo y agitado, me fui adormeciendo, y al cabo, tuve el siguiente sueño», p. 96. 
«Al llegar al redil o aprisco que por acá llaman paridera, vi que los pastores nada tenían de sencillos, halagüeños, ni poéticos, sino mucho de taimados, bozales y aun estoy por decir barroqueños, pues miraban a todos con recelo, y contestaban siempre con ferocidad, sin cesar de maldecir y apalear brutalmente a aquellos tímidos e indefensos animalillos, que tienen la desgracia de ser sus rendidos súbditos» ${ }^{29}$.

Esta descripción evidencia que Mor de Fuentes prefirió abandonar la preceptiva poética clásica para representar la realidad del campo y pintó a los pastores tales como eran, aunque personalmente era aficionado a los versos de Meléndez Valdés ${ }^{30}$. En una novela, ya no había cabida para el código pastoril de representación de la realidad. Finalmente, la Serafina marca una etapa en la autonomía del género en cuanto a la preceptiva clásica y no sólo en el estilo, como lo pensaba el propio autor, sino también en las técnicas narrativas ${ }^{31}$. El espacio novelesco se aleja de sus referencias literarias, en particular del topos del «menosprecio de corte y alabanza de aldea», para imitar la realidad concreta, con sus hermosuras y sus imperfecciones.

La novela del final del siglo XVIII recupera el «menosprecio de corte y alabanza de aldea» integrándolo en un marco narrativo. Como lo analizamos, este topos moral no sólo sirve el desarrollo de la acción sino que también integra una temática de índole económica. Así, la novela asimila elementos clásicos, tomados de los géneros nobles, pero readaptándolos a sus propias características e intenciones. Sin embargo, el caso de La Serafina nos lleva a considerar la especificidad del mundo ficticio de la novela. Al abandonar cualquier idealización del mundo rural, Mor de Fuentes marca la autonomía del género respecto a las poéticas clásicas en cuanto a la representación del espacio. Éste, siguiendo la tendencia que se había impuesto para los personajes, va a ganar en profundidad y en particularidad. Después de la desaparición progresiva de los personajes tipos intercambiables, los decorados fijos e inmóviles cederán el paso a espacios cuyas referencias son la vida y la actualidad.

29 José MOR DE FUENTES, La Serafina, p. 170.

30 José MOR DE FUENTES, La Serafina, p. 113. Por la boca de Alfonso expresa esta admiración: «Viva millares de siglos el tierno, el armonioso, el castizo Meléndez, que en sus divinos Romances Pastoriles sabe arrebatar y enloquecer los corazones inocentes tras los únicos objetos apreciables de la Naturaleza, como son árboles, mieses, flores, arroyos, aves, rebaños [...]».

31 A este propósito, no hemos podido consultar el libro de Magda RUGGERI MARCHETTI, Studio su «la Serafina» di José Mor de Fuentes, Bulzoni, Roma, 1986 señalado por Guillermo CARNERO, «La novela española del siglo XVIII: estado de la cuestión (19851994)», en Francisco LA RUBIA PRADO y Jesús TORRECILla, Razón tradición y modernidad, revisión de la Ilustración hispánica, Madrid, Técnos, 1996, p. 40. 